Article

\title{
The time pattern of selenomethionine administration in preventing free radicals due to exposure to electric cigarette smoke
}

\author{
Rivan Virlando Suryadinata, ${ }^{1}$ Bambang Wirjatmadi, ${ }^{2}$ Amelia Lorensia ${ }^{3}$ \\ ${ }^{1}$ Faculty of Medicine, Universitas Surabaya (UBAYA), Surabaya; ${ }^{2}$ Faculty of Public Health, Airlangga \\ University, Surabaya; ${ }^{3}$ Faculty of Pharmacy, Universitas Surabaya (UBAYA), Surabaya, Indonesia
}

\begin{abstract}
Background: Most people believe that electric cigarettes have no negative effect on health, which causes them to use it more. However, exposure to the smoke from these cigarettes is bad for the health and causes cell damage. Antioxidants play an important role in preventing cell damage, and they can be obtained through the oral administration of selenomethionine.

Design and methods: This study used an experimental method and a post-test control group design. Male Wistar rats, which were exposed to cigarette smoke were given selenomethionine orally and then tested for the presence of free radicals. The measurement of lung tissue damage was conducted by assessing the level of malondialdehyde in the blood and immunohistochemistry (IHC) of the lung tissue.

Result: The study showed that differences in the time of administration of selenomethionine affect the levels of malondialdehyde in the blood and expression of malondialdehyde in the lung tissue $(\mathrm{p}<0.05)$. Consequently, the two groups showed a strong $(r=0.861)$ and significant $(\mathrm{p}=0.000)$ relationship with each other.

Conclusion: The early application of selenomethionine can prevent increased levels of malondialdehyde in the blood and lung tissue due to exposure to e-cigarette smoke.
\end{abstract}

\section{Introduction}

The use of electric cigarettes has increased in many countries due to the rising popularity and its alleged benefits. ${ }^{1}$ The main reasons for using electric cigarettes are that they reduce the dependence of tobacco cigarettes, they are safer for smokers, and the smoke emitted does not disturb the surrounding environment. ${ }^{2}$ However, the effectiveness and benefits of using these cigarettes both in the short and long term have not been proven through clinical trials. ${ }^{3}$ Furthermore, these cigarettes have not been named as a solution to smoking. The combined use of tobacco and electric cigarettes will further extend the use of both, as electric cigarettes are often used in places which prohibit the use of the tobacco variety. ${ }^{4}$ An electric cigarette is an electronic product that uses energy from batteries to heat up liquid containing either propylene glycol, glycerin, nicotine, and various flavors. This process produces aerosols which can be inhaled by its users. ${ }^{5}$ Electric cigarettes as product have a variety of attractive models and good marketing methods, which make them not only substitutes for cigarettes, but also trend setters for teenagers. This will lead to an increase in the number of electric cigarette smokers in the young age group. ${ }^{6}$ A very aggressive promotion and marketing system has been detected in several countries through the very significant increase in promotional costs which are expected to double every year. ${ }^{7}$

Smoke produced from electric cigarettes contain various harmful substances which can increase the number of free radicals (Reactive Oxygen Species and Reactive Nitrogen Species) in the body to high concentrations of around $10^{16}$ molecules/puff. ${ }^{8}$ Free radicals are normal cellular metabolic products that contain one or more unpaired electrons. ${ }^{9}$ Normally, they are useful to the body's immune system and are produced during metabolic reactions involving oxygen. Excessive increase in free radicals will cause an imbalance between free radicals and antioxidants in the body, triggering oxidative stress. ${ }^{10}$ This will affect cellular pathways such as metabolism, proliferation and inflammatory processes in cells. In addition, cell damage caused by free radicals can induce various ailments such as cancer, cardiovascular, and pulmonary disease. ${ }^{11,12}$ An increase in the amount of excess free radicals can also cause lipid peroxidation reactions which will lead to cell damage and death. ${ }^{13}$ However, free radicals in the body can be directly neutralized by enzymatic antioxidants.

Giving additional antioxidant is needed to increase enzymatic antioxidants that can help neutralize external free radicals. This antioxidant can only be produced in the body, therefore additional intake only helps to increase its activity. Malondialdehyde is an indicator for increasing enzymatic antioxidant activity, because it is one of the final end products of lipid peroxidation. Therefore, changes in malondialdehyde can be used as a benchmark for the reduction or increase of free radicals in the body. ${ }^{14}$ Antioxidants are the main defense in preventing the accumulation of free radicals in the system. The three main enzymatic antioxidants that perform these roles are superoxide dismutase (SOD), catalase (CAT) and glutathione peroxidase (GSH-Px). Selenomethionine is a micronutrient that can stimulate antioxidant activity in the body. ${ }^{15}$ It can be obtained from various food sources such as vegetables,

Significance for public health

The use of e-cigarettes has a negative impact on health, because they cause an increase in the free radicals in the body. Meanwhile, these free radicals cause cellular damage in the airways, which is evidenced by an increase in malondialdehyde levels, and can be detected in the blood and lung tissues. Selenomethionine can stimulate an increase in enzymatic antioxidant activity which leads to the neutralization of free radicals. Therefore, oral administration of selenomethionine can prevent the buildup of these radical in the blood and lung tissues. 
seafood, meat, dairy products and various types of nuts. However, the main form of selenomethionine that is digested by humans is L-selenomethionine. Besides increasing the antioxidant activity of L-selenomethionine, Selenomethionine also acts as an anti-inflammatory and works with the immune system. ${ }^{16}$

Various studies have shown the negative effects of electronic cigarettes, however, an assessment on the long-term damage to lung tissue has not been widely pursued. This is because, to prove the long-term negative effects of electric cigarettes, there must be evidence showing progressive cell damage due to exposure to electric cigarette smoke. In addition, various attempts have been made to reduce the impact of cell damage caused by free radicals. This form of damage will directly affect the expression of cells in lung tissue. Therefore, the purpose of this study is to analyze the time difference effect of per-oral selenomethionine in inhibiting free radicals both in the body and in the intracellular lung tissue. It also observed the association between increased free radicals in blood and the damage to lung cells through the expression of malondialdehyde in lung tissue.

\section{Design and Methods}

This is an experimental study using post-test control group design. Sample of this study were male Wistar rats (Rattus novergicus). The samples were divided into 6 groups (including negative control groups, positive control groups and treatment groups), each having different treatments. These rats were exposed to cigarette smoke for 2 minutes every day for 28 days. After oral administration of selenomethionine and exposure to e-cigarette smoke, an assessment of malondialdehyde levels through blood and lung tissue observations was performed using Immunohistochemistry (IHC) staining. This study aims to observe and compare lung tissue damage and also determine the effectiveness of selenomethionine in reducing free radicals by increasing antioxidant activity.

The Wistar rat was the experimental animal used in this study. Some requirements for the rats were given to make the sample homogeneous, such as: being 2-3 months old with a weight of 150200 grams, no macroscopic abnormalities, and never been used as the object of research. The study was conducted at the Laboratory of the Faculty of Medicine, University of Surabaya. Each group was given selenomethionine orally and exposed to e-cigarette smoke at different time, amount and duration of administration.

Malondialdehyde in the blood was measured using the Thiobarbituric Acid Reactive Substance (TBARS) Assay. This assay was are carried out directly and accurately using the Bioassay System. The color intensity was measured at $535 \mathrm{~nm}$ with a fluorescence intensity of $560 \mathrm{~nm} / 585 \mathrm{~nm}$ which is directly proportional to the concentration of TBARS. Histological examination using the modified Remmele method was performed to determine intracellular malondialdehyde expression and was assessed as semiquantitative. The Remmele scale index (Immuno Reactive Score/IRS) is obtained by multiplying the percentage score of immunoreactive cells with that of the color intensity. The data for each sample was the average value of the IRS which was observed in 5 (five) different Fields of View (LP) using a light microscope at 1000x magnification.

In this study, the experimental animals were divided into 6 groups. Each group was given a different treatment: 1) Group I = this control group was given only food with no treatment for 4 weeks; 2) Group II = this group was given food and treatment by exposing them to electric cigarette smoke, but without the administration of selenomethionine for 4 weeks; 3) Group III = this group was given food and selenomethionine (with the dose of 3.6 mcg / h / tail) without electric cigarette smoke exposure for 4 weeks; 4) group IV = this group at the beginning of the treatment was exposed to cigarette smoke for 1 week after which it was then exposed to electric cigarette smoke and administered selenomethionine (dose of $3.6 \mathrm{mcg} / \mathrm{hr} / \mathrm{tail}$ ) for 4 weeks; 5) group $\mathrm{V}=$ this group was given food, exposed to electric cigarette smoke, and administered selenomethionine (dose $3.6 \mathrm{mcg} / \mathrm{day} /$ tail) from the beginning of the treatment, for 4 weeks; and 6) group VI = this group at the beginning of the treatment was given selenomethionine (dose of $3.6 \mathrm{mcg} / \mathrm{day} / \mathrm{head}$ ) for $1 \mathrm{week}$, then it was exposed to electric cigarette smoke and administered selenomethionine (dose of $3.6 \mathrm{mcg} / \mathrm{day} / \mathrm{head}$ ) for the remaining 4 weeks.

Statistical tests using ANOVA were performed on the data collected. This was done to determine differences in malondialdehyde levels in the blood and lung tissue. Subsequently, the Least Significant Differences test was performed to compare groups, after which a correlation test was performed to see the relationship between two groups.

\section{Result and Discussions}

\section{Malondialdehyde levels in the blood due to exposure to e-cigarette smoke}

The study was obtained by comparing the levels of malondialdehyde in the blood and lung tissue of each group. The mean value of malondialdehyde in the blood was proportional to the duration of exposure to cigarette smoke and selenomethionine. Malondialdehyde level in group III recorded the lowest value of $2.15 \pm 0.33$, while the highest value in group II which was $5.02 \pm 0.51$. The results of the study were analyzed by the KruskalWallis test, because the data obtained did not meet the requirements for normality and homogeneity tests $(\mathrm{p}<0.05)$. Consequently, the Kruskal-Wallis analysis of malondialdehyde levels showed differences in various groups $(\mathrm{p}=0.000)$ (Table 1$)$.

\section{Malondialdehyde expression due to exposure to e-cigarette smoke}

The results were also obtained by comparing the mean levels of malondialdehyde in each group per 5 fields of view. Table 2 shows the mean value and standard deviation of malondialdehyde in each group. These results showed an increase in malondialdehyde level in each group was directly proportional to the length of time of exposure to cigarette smoke and selenomethionine. In group I and III, the mean malondialdehyde value was $1.36 \pm 0.17$ which was the lowest mean value in all groups. While the highest

Table 1. The mean value and Kruskal-Wallis test for malondialdehyde.

\begin{tabular}{llcc} 
Groups & & Mean \pm SD & p-value \\
I & Control negative & $2.69 \pm 0.17$ & 0.000 \\
II & Control positive cigarette & $5.02 \pm 0.51$ & 0.000 \\
\hline III & Control positive selenomethionine & $2.15 \pm 0.33$ & 0.000 \\
IV & Treatment group I & $3.20 \pm 0.23$ & 0.000 \\
\hline V & Treatment group II & $3.81 \pm 0.22$ & 0.000 \\
VI & Treatment group III & $4.26 \pm 0.13$ & 0.000 \\
\hline
\end{tabular}


mean value was obtained in group II which reached $10.20 \pm 0.42$. Figure 1 shows that the control group's (group 1) lung tissue had a lower color intensity than the other groups. Furthermore, the ANOVA test was used to mark the different expressions of malondialdehyde in various groups of which the results are shown in $(\mathrm{p}=0.000)$ (Table 3). The correlation test analysis showed strong relationship between malondialdehyde levels in the blood and lung tissue $(\mathrm{r}=0.861 ; \mathrm{p}=0.000)$ (Table 3$)$.

Most people assume that electronic cigarettes have no negative effects and are safer than tobacco cigarettes. Such false perceptions make the use of these products increase every year. ${ }^{17}$ In recent times, adolescents and young adult smokers seek electric cigarettes as nicotine alternatives without the harmful side effects. ${ }^{18}$ Even young people nonsmokers will want to try new things, which leads them to form new habits. ${ }^{19}$ Inhaled electric cigarette smoke increases the production of free radicals by reacting with other chemicals such as aldehydes, polycyclic aromatic hydrocarbons (PAHs) and heavy metals. ${ }^{20}$ This further increases the inflammatory response in the body. Chronic cigarette smoke exposure can cause cell damage (due to oxidative stress) and this is an important factor in the etiology of various diseases caused by smoking. ${ }^{21}$ Many studies show the negative impact of cigarette smoke exposure in different perspectives, however there were those that foresaw the danger behind the contents of electric cigarettes liquids when heated. ${ }^{22,23}$ In addition, the use of these cigarettes caused free radicals to be were also observed in the body through the blood ${ }^{24}$ However, the existence of intracellular damage in the lung tissue has not yet been proven.

One of the free radicals that comes from oxygen oxidation is superoxide $\left(\mathrm{O}_{2} \bullet^{-}\right)$. It is neutralized by the superoxide antioxidant

Table 2. ANOVA test results for malondialdehyde.

\begin{tabular}{lcccc} 
Group & Mean \pm SD & Maximal & Minimal & ANOVA test \\
I & $1.36 \pm 0.17$ & 1.6 & 1.2 & 0.000 \\
II & $10.20 \pm 0.42$ & 9.6 & 10.6 & 0.000 \\
\hline III & $1.36 \pm 0.17$ & 1.6 & 1.2 & 0.000 \\
IV & $7.92 \pm 0.48$ & 8.4 & 7.4 & 0.000 \\
V & $9.44 \pm 0.33$ & 10 & 9.2 & 0.000 \\
VI & $10.08 \pm 0.39$ & 10.6 & 9.6 & 0.000 \\
\hline
\end{tabular}

Table 3. Correlation test between levels of malondialdehyde in the blood and lung tissue.

$\begin{array}{lcc}\text { Variables } & \text { Correlation test } & \text { P-value } \\ \text { Blood malondialdehyde } & 0.861 & 0.000 \\ \text { Expression of malondialdehyde in the lung tissue } & & \end{array}$
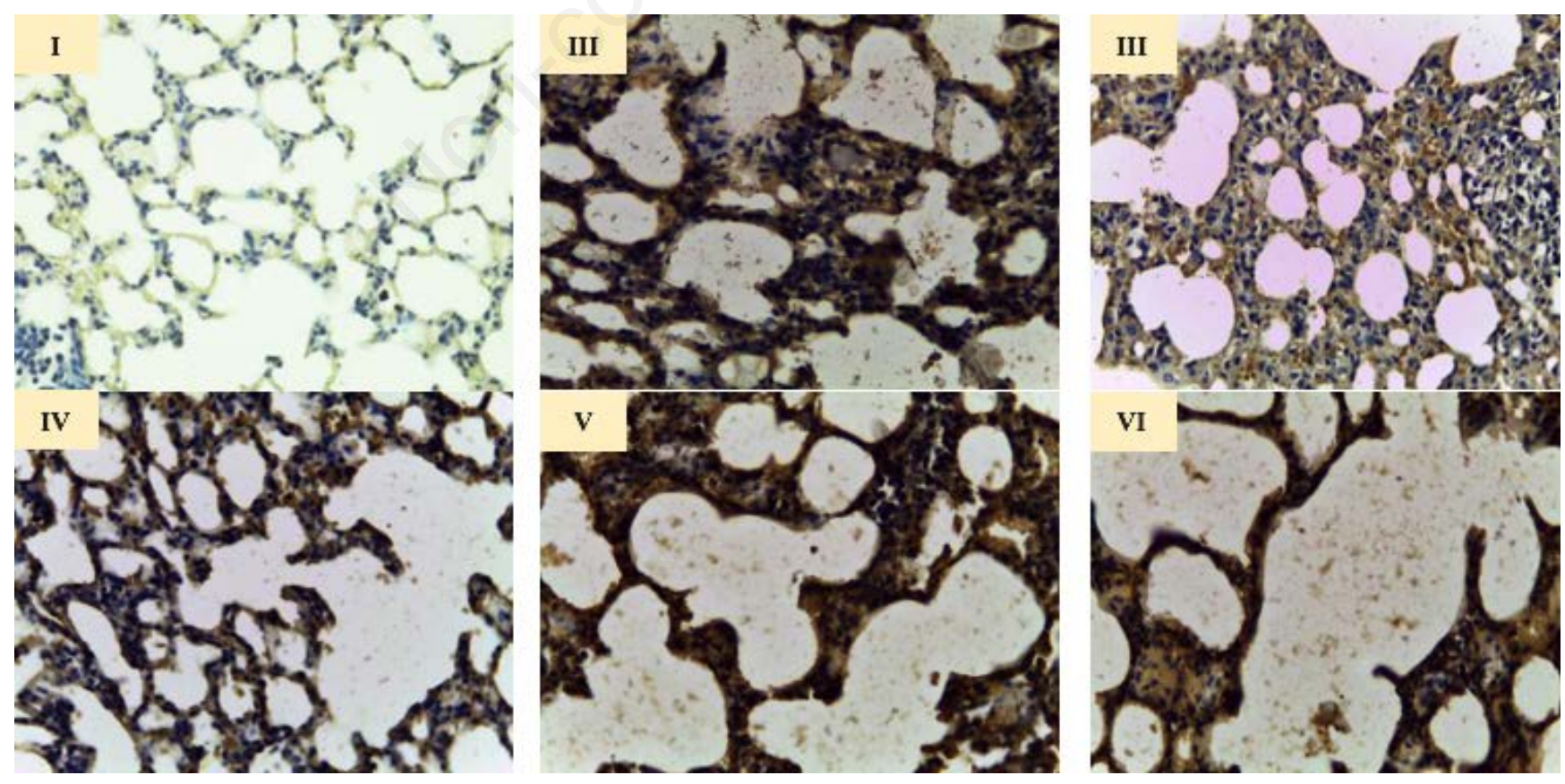

Figure 1. Expression of malondialdehyde in the lung tissue. 
and mutated to become hydrogen peroxidase $\left(\mathrm{H}_{2} \mathrm{O}_{2}\right)$ radicals. These are all non-reactive radicals, but when they experience a Fenton and Haber-Weiss reaction, they will turn into reactive hydroxyl $(\bullet \mathrm{OH})$ radicals. ${ }^{25}$ However, the hydrogen peroxidase radical can be converted back into water and oxygen by action of the antioxidant glutathione peroxidase (GSH-Px) and catalase (CAT). Selenomethionine is a micronutrient that plays a major role in increasing the activity of glutathione peroxidase. Therefore, increasing selenomethionine intake can help boost the activity of antioxidants from the body, thereby reducing the effects of cell damage. ${ }^{26}$

\section{Conclusions}

The results showed that early administration of selenomethionine, was effective in preventing and reducing free radicals in the body. This was proven by the reduction in free radicals in the groups which were given oral selenomethionine early. In addition, exposure of electronic cigarette smoke to the airway not only increases free radicals in the blood, but also within the cell. This is observed from the increased levels of malondialdehyde not only in the blood, but also in the expression of malondialdehyde in the pulmonary alveoli. Therefore, the impact of exposure to electronic cigarette smoke not only influences free radicals in the body, but also affects the intracellular system.

Correspondence: Rivan Virlando Suryadinata, Faculty of Medicine, Universitas Surabaya (UBAYA), Surabaya, Jl. Tenggilis Mejoyo, Kali Rungkut, Kec. Rungkut, Kota SBY, Jawa Timur 60293, Indonesia. Tel.+62.31.2981000. E-mail: rivan.virlando.s@staff.ubaya.ac.id

Key words: Malodialdehyde; e-cigarette; immunohistochemistry; lung tissue.

Acknowledgements: The authors are grateful to the team that have helped with this research.

Contributions: All authors contributed equally to this study.

Conflict of interest: The author declares there was no conflict of interest.

Ethics approval: This study was approved by the Health Research Ethics Committee of the Faculty of Public Health, University of Airlangga.

Conference presentation: Part of this study was presented at the $1^{\text {st }}$ International Nursing and Health Sciences Symposium, November $13^{\text {th }}$ to $15^{\text {th }} 2020$, Brawijaya University, Malang, Indonesia

Received for publication: 17 January 2021.

Accepted for publication: 12 March 2021.

o Copyright: the Author(s), 2021

Licensee PAGEPress, Italy

Journal of Public Health Research 2021;10:2232

doi:10.4081/jphr.2021.2232

This work is licensed under a Creative Commons Attribution NonCommercial 4.0 License (CC BY-NC 4.0).

\section{References}

1. Delnevo CD, Giovenco DP, Steinberg MB, et al. Patterns of electronic cigarette use among adults in the United States. Nicotine Tob Res 2016;18:715-9.

2. Zhu S-H, Gamst A, Lee M, et al. The use and perception of electronic cigarettes and snus among the U.S. population. PLoS One 2013;24:e79332.

3. Zhuang Y-L, Cummins SE, Y Sun J, et al. Long-term e-cigarette use and smoking cessation: a longitudinal study with US population. Tob Control 2016;25:190-5.

4. Rutten LJF, Blake KD, Agunwamba AA, et al. Use of e-cigarettes among current smokers: associations among reasons for use, quit intentions, and current tobacco use. Nicotine Tob Res 2015;17:1228-34

5. Hua M, Talbot P. Potential health effects of electronic cigarettes: A systematic review of case reports. Prev Med Reports 2016;4:169-78.

6. Amrock SM, Lee L, Weitzman M. Perceptions of e-cigarettes and noncigarette tobacco products among US youth. Pediatrics 2016;138:e20154306

7. Xu Y, Guo Y, Liu K, et al. E-cigarette awareness, Use, and harm perception among adults: A meta-Analysis of observational studies. PLoS One 2016;11:e0165938.

8. Goel R, Durand E, Trushin N, et al. Highly reactive free radicals in electronic cigarette aerosols. Chem Res Toxicol 2015;28:1675-7

9. Phaniendra A, Jestadi DB, Periyasamy L. Free radicals: Properties, sources, targets, and their implication in various diseases. Indian J Clin Biochem 2015;30:11-26.

10. Suryadinata RV. Effect of free radicals on inflammatory process in chronic obstructive pulmonary disease (COPD). Amerta Nutr 2018;2:317-24.

11. Messner B, Bernhard D. Smoking and cardiovascular disease. Arterioscler Thromb Vasc Biol 2014;34:509-15.

12. Domej W, Oetll K, Renner W. Oxidative stress and free radicals in COPD - implications and relevance for treatment. Int $\mathrm{J}$ Chron Obstruct Pulmon Dis 2014;9:1207-24.

13. Suryadinata RV, Wirjatmadi B, Adriani M, et al. Effects of knowledge of vitamin $\mathrm{D}$ on attitudes toward sun exposure among middle-aged and elderly Indonesian adults. Indian $\mathrm{J}$ Public Heal Res Dev 2018;9:11-5.

14. Suryadinata RV, Wirjatmadi B, Adriani M, et al. The effects of exposure duration to electronic cigarette smoke on differences in superoxide dismutase and malondialdehyde in blood of Wistar rats. Int J Curr Pharm Res 2019;11:13-6.

15. Zoidis E, Seremelis I, Kontopoulos N, et al. Selenium-dependent antioxidant enzymes: Actions and properties of selenoproteins. Antioxidants 2018;7:66.

16. Huang Z, Rose AH, Hoffmann PR. The role of selenium in inflammation and immunity: From molecular mechanisms to therapeutic opportunities. Antioxid Redox Signal 2012; 16:705-43.

17. Baeza-Loya S, Viswanath H, Carter A, et al. Perceptions about e-cigarette safety may lead to e-smoking during pregnancy. Bull Menninger Clin 2014;78:243-52.

18. Choi K, Forster J. Characteristics associated with awareness, perceptions, and use of electronic nicotine delivery systems among young US midwestern adults. Am J Public Health 2013;103:556-61.

19. Ling PM, Glantz SA. Why and how the tobacco industry sells cigarettes to young adults: Evidence from industry documents. Am J Public Health 2002;92:908-16. 
20. Crotty Alexander LE, Shin S, Hwang JH. Inflammatory diseases of the lung induced by conventional cigarette smoke. Chest 2015;148:1307-22.

21. Mons U, Muscat JE, Modesto J, et al. Effect of smoking reduction and cessation on the plasma levels of the oxidative stress biomarker glutathione - Post-hoc analysis of data from a smoking cessation trial. Free Radic Biol Med 2016;91:172-7.

22. Bitzer ZT, Goel R, Reilly SM, et al. Effects of solvent and temperature on free radical formation in electronic cigarette aerosols. Chem Res Toxicol 2018;31:4-12.

23. Pankow JF, Kim K, Luo Wm et al. Gas/particle partitioning constants of nicotine, selected toxicants, and flavor chemicals in solutions of 50/50 propylene glycol/glycerol as used in elec- tronic cigarettes. Chem Res Toxicol 2018;31:985-90.

24. Hu J-P, Zhao X-P, Ma X-Z, et al. Effects of cigarette smoke on aerobic capacity and serum MDA content and SOD activity of animal. Int J Clin Exp Med 2014;7:4461-5.

25. Suryadinata RV, Wirjatmadi B. Selenium linked to increased antioxidant levels and decreased free radical in lung tissue of Wistar rats exposed to e-cigarette smoke. J Global Pharma Technol 2020;12:32-9.

26. Sedighi O, Zargari M, Varshi G. Effect of selenium supplementation on glutathione peroxidase enzyme activity in patients with chronic kidney disease: A randomized clinical trial. Nephrourol Mon 2014;4:6:e17945. 